\title{
Effect of Sr, Zn, and Ce Substitution on the Properties of Bioactive Glasses
}

\author{
Irina Atkinson* \\ Department of Oxide Compounds and Materials Science, Institute of Physical Chemistry of the Romanian Academy, Romania
}

*Corresponding author: Irina Atkinson, Institute of Physical Chemistry of the Romanian Academy Bucharest 202 Splaiul Independentei, 060021 Bucharest, Romania.

To Cite This Article: Irina Atkinson, Effect of Sr, Zn, and Ce Substitution on the Properties of Bioactive Glasses. 2020 - 10(1). AJBSR.MS.ID.001467. DOI: 10.34297/AJBSR.2020.10.001467.

Received: 眥 July 29, 2020; Published: 眥 August 21, 2020

\begin{abstract}
As well as improving the life of people of all ages, a rise in the life expectancy of people has led to an increased demand for new restoring and augmentation materials that have applications in therapies for bone pathologies. Bioactive Glasses (BGs) have revolutionized the field of biomaterials as they have been generally accepted to be able to promote both hard and soft living tissues regeneration and self-repair. This brief review will discuss the effect of metallic ions substitution on the properties of bioactive glasses for tissue engineering and regenerative medicine applications.
\end{abstract}

\section{Bioactive Glasses an Overview}

The discovery and development of materials that interface with living host tissue i.e. fusion and co-joining of biomaterials with the human body are of great interest in the field of medical implants. A large amount of scientific effort has been devoted to find and manufacture biomaterials with improved properties. Traditionally, Bioactive Glasses (BGs) have been used to fill and restore bone defects. Recently, a high number of studies investigated and suggested BGs for bone replacement or skin repair and regeneration [1-5].

BGs are playing a fundamental role in the field of biomaterials due to their osteoconductive, osteo productive and osteo inductive properties. Prof. Hench [6], who initiated this subject of research with his colleagues in the early 1970s [6], gave us a good definition of bioactive materials; "A bioactive material is one that elicits a specific biological response at the interface of the material which results in the formation of a bond between the tissues and the material", Hench and his research team discovered that a certain composition of glass in the system $\mathrm{SiO}_{2}-\mathrm{CaO}-\mathrm{Na}_{2} \mathrm{O}-\mathrm{P}_{2} \mathrm{O}_{5}$ was able to form a bond with bone once they are implanted. In fact, when these BGs are immersed biological fluids, a layer of Hydroxyapatite (HA) is deposited on their surface. The 45S5 bioactive glass composition, known as Bio glass (composition in wt.\%: $45 \% \mathrm{SiO}_{2}, 24.5 \% \mathrm{Na}_{2} \mathrm{O}$, $24.5 \% \mathrm{CaO}$ and $6 \% \mathrm{P}_{2} \mathrm{O}_{5}$ ), has approval of the US Food and Drug Administration (FDA). 4555 Bioglass is used in clinical treatments of periodontal diseases as bone filler as well as in middle ear surgery [7].

Bioactive Glasses (BGs) can be produced either by a traditional melt-quenching method or a sol-gel route. Three main BG production techniques are of most interest. The melt quenching technique is the traditional technique for the production of BGs [8]. The synthesis includes melting oxides of i.e. silica, calcium, and phosphate in adequate proportions according to the desired composition at temperature of around $1300{ }^{\circ} \mathrm{C}$ in a platinum crucible and quenched in a mold or in water (fritting procedure)Annealing at $500{ }^{\circ} \mathrm{C}$ of the quenched glass is required to remove the internal stresses from the glasses [8].

In the early 1990s BGs were for the first time prepared by the sol-gel process by Li et. al. [9] in an effort to overcome the limitations of melt derived BGs (synthesis at high temperature, lack of microporous structure, and a low specific surface) [10]. 
Porous bioactive glasses can be prepared from the hydrolysis and polymerization of metal alkoxides and/or organic or inorganic salts at low temperature. This synthesis method allows you to obtain materials with high specific surface area $200-650 \mathrm{~m}^{2} / \mathrm{g}$ and high porosity [11]. In addition, due to the high surface area and porosity derived from the sol-gel process, the range of bioactive compositions is wider, and also exhibit higher bone bonding rates together with excellent degradation/resorption properties [12] Hydroxyapatite (HA) is deposited much faster on sol-gel BGs due to their higher porosity than on traditional melt derived glasses and these materials can be resorbed, in some cases [11]. In fact, the porous structure of sol-gel bioactive glasses allows the formation of a hydrated layer inside the material, where biological moieties can enter maintaining their structural configuration and biological activity.

Sol-gel process can be combined with supramolecular chemistry of surfactants, resulting the third generation of highly ordered Mesoporous Bioactive Glasses (MBGs) [13,14]. The structure-directing agents used for fabrication of MBGs (CTAB, F127 and P123) influence the mesopore structure, mesopore size, surface area and pore volume of MBGs. MBGs can be used as multifunctional systems as a carrier for drugs, growth factors or other biomolecules. Moreover, BGs and MBGs can be foamed to produce macroporous scaffolds with interconnected macro pores enhancing the bioactive behaviour as well as the release of ionic products [15].

The drawback of current treatments (e.g. high cytotoxic effects of alkali containing BGs) $[16,17]$ and the impact on healthcare costs have focused scientific efforts to develop alkali free bioactive glasses for applications in tissue engineering. In addition to $\mathrm{SiO}_{2}, \mathrm{CaO}, \mathrm{P}_{2} \mathrm{O}_{5}$ other metallic ions can be incorporated in the glass composition to improve their properties and add new biological functions [1822]. In this review, the progress in the use of several metallic ions Strontium (Sr), Zinc (Zn), and Cerium (Ce), on the therapeutic properties of BGs is highlighted.

Effect of $\mathrm{Sr}, \mathrm{Zn}$, and $\mathrm{Ce}$ incorporation on the properties of BGs

In recent years, new compositions of BGs with high bioactivity and new functionalities (e.g enhanced bone formation and angiogenesis, antimicrobial properties) induced by the ions release from the glass structure into the surrounding biological environment were produced [23-26]. The ionic dissolution of BGs stimulates the expression and secretion of biochemical markers: Osteocalcin (OCN), Osteopontin (OPN), and Vascular Endothelial Growth Factor (VEGF) involved in the repair and regeneration of bone [27].

Strontium (Sr) is a naturally occurring trace element in the human body. The total amount of strontium in the body is 0.335 g of its Ca content [28]. The biological features of Sr are similar to Ca in the human body, both have strong bone-seeking properties $[29,30]$. Nowadays strontium is used as a commercial oral drug to treat osteoporosis by stimulating the formation of new bone and preventing osteoclast-mediated resorption [31]. Sr is the only element among the ones present in human bone that is correlated with bone compression strength [32]. Wu et al. [33] reported that the Sr containing mesoporous BG scaffolds stimulates the osteogenic differentiation of periodontal ligament cells, which clearly induced osteoblast activity. Recent investigation has shown ability of Sr doped BGs obtained by sol-gel method to promote proliferation, early odontogenic differentiation and mineralization of human dental pulp cells [33].

Among doping elements, Zinc (Zn) has received special interest in the recent years due to its potential benefits. $\mathrm{Zn}$ is a cofactor for many enzymes, by stimulating protein synthesis which is essential in DNA replication. Furthermore, it has an important role in bone cell growth, development and differentiation [34-36]. Zinc deficiency can be associated with delay in bone tissue calcification and skeletal growth retardation [37]. Also, Zn has antibacterial activity and can have beneficial effect on the mechanical strength of the BGs [38]. Effect of the ZnO substitution on the biocompatibility of BGs has been studied by different research groups [18,39]. Sanchez-Salcedo et al. [40] reported antimicrobial activity against staphylococcus aureus and good biocompatibility of the scaffolds with $7 \mathrm{~mol} \% \mathrm{ZnO}$ addition. Very good antimicrobial activity against P. aeruginosa and B. subtilis strains was achieved by Zn containing MGBs doped with $5 \mathrm{~mol} \% \mathrm{ZnO}$ [18]. ZnO can act both as a network modifier or an intermediate oxide in the BG structure. By increasing the $\mathrm{ZnO}$ content its role is switched from a network modifier to an intermediate oxide and hence can influence BG properties. S. Shahrabi et al. [41] have shown that $5 \mathrm{~mol} \% \mathrm{ZnO}$ may reduce the number of nonbridging oxygen atoms, and hence decrease the glass bioactivity [41]. Similar results were reported by [18].

In the last years cerium $(\mathrm{Ce})$ has received special attention due to its beneficial biological features, antibacterial properties and in vitro positive effect on primary mouse osteoblasts $[42,43]$.

Recently several studies reported the effects of the addition of Ce to the BG properties. Thus, Shruti et al [44] evaluated the bioactivity of scaffold based on Ce containing MBGs. High content of cerium determines a decrease of BG bioactivity due to crystallization of $\mathrm{CePO}_{4}$ that came out and agglomerated on the surface of BG, impeding the formation of HA layer on the surface [45]. Recently, Atkinson et al. reported that increasing ceria content improves chemical durability of MBGs containing $5 \mathrm{~mol} \%$ of $\mathrm{CeO}_{2}$ and its bioactivity was not altering significantly (a deficient HA was formed) [19]. Incorporation of cerium into BGs can enhance their antioxidant activity inducing anti-inflammatory, pro-osteogenesis, 
and pro angiogenesis activities [46]. V Nicolini [47] studied the catalase mimetic activity of Ce-containing BGs based on 45S5 composition and reported that these BGs have the ability to inhibit oxidative stress, by mimicking the catalase and superoxide dismutase activity. Good bioactivity and antibacterial response against Escherichia coli of BGs with 1, 5, $10 \mathrm{~mol} \mathrm{\%} \mathrm{CeO}_{2}$ were reported by Goh et al. [42]. Beside its beneficial effects mentioned above, Ce also is known as a neuroprotective agent being involved in peripheral nerve regeneration [48].

Despite these advantages of ceria over other therapeutic strategies, there are still toxicity issues to be considered [49]. However, recent investigations have shown that MBGs containing Ce have no cell cytotoxic activity on L929 cells [19].

\section{Conclusion}

In this paper, the effect of the substitution of several key ions, including strontium, zinc, and cerium on BGs therapeutic properties was summarized. A large volume of research is focused on obtaining doped BGs with enhanced biological activity. These metallic ions are added to the BG formulation to impart therapeutic features, but they also can change the properties of BG, such as altering the bioactivity and rate of HA formation. Attractive biomaterials for tissue engineering applications can be obtained by incorporation of $\mathrm{Sr}, \mathrm{Zn}$ and, Ce in their formulation.

\section{References}

1. Souza MT, Rennó ACM, Peitl O, Zanotto ED (2017) New highly bioactive crystallization-resistant glass for tissue engineering applications. Transl Mater Res 4(1): 014002.

2. Cai L, Mao C, Zhang J, Li Y, Chen X (2012) Healing effect of bioactive glass ointment on full-thickness skin wounds. Biomed Mat 7(4): 045017.

3. Balasubramanian P, Büttner T, Pacheco VM, Boccaccini AR (2018) Boron-containing bioactive glasses in bone and soft tissue engineering. J Eur Ceram Soc 38(3): 855-869.

4. Kargozar S, Lotfibakhshaiesh N, Ai J, Mozafari M, Milan PB, et al. (2017) Strontium- and cobalt-substituted bioactive glasses seeded with human umbilical cord perivascular cells to promote bone regeneration via enhanced osteogenic and angiogenic activities. Acta Biomater 58: 502514.

5. Jones JR, Brauer DS, Hupa L, Greenspan DC (2016) Bioglass and Bioactive Glasses and their Impact on Healthcare. Int J Appl Glass Sci 7(4): 423434.

6. Hench LL, Splinter RJ, Allen WC, Greenlee TK (1971) Bonding Mechanisms at the Interface of Ceramic Prosthetic Materials. J Biomed Mater Res 2(1): 117-141

7. Hench LL (2006) The story of bioglass. J Mater Sci Mater Med 17(11): 967-978.

8. Kaur G, Pandey OP, Singh K, Homa D, Scott B, et al. (2014) A review of bioactive glasses: Their structure, properties, fabrication, and apatite formation. J Biomed Mater Res Part A 102(1): 254-274.

9. Li R, Clark AE, Hench LL (1991) An investigation of bioactive glass powders by sol-gel processing. J Appl Biomater 2(4): 231-239.

10. Hench LL (1998) Biomaterials: a forecast for the future. Biomaterials 19(16): 1419-1423.
11. Avnir D, Braun S (1996) Biochemical aspects of sol-gel science and technology: a special issue of the journal osol-gel science and technology. Springer-Verlag, New York, USA. pp.144.

12. Yan X, Yu C, Zhou X, Tang J, Zhao D (2004) Highly ordered mesoporous bioactive glasses with superior in vitro bone-forming bioactivities. Angew Chem Int Ed Engl 43(44): 5980-5984.

13. Wang Y, Liao T, Shi M, Liu C, Chen X (2017) Facile synthesis and in vitro bioactivity of radial mesoporous bioactive glasses. Mat Lett 206: 205209.

14. Kargozar S, Mozafari M, Hamzehlou SH, Kim W, Baino F (2019) Mesoporous Bioactive Glasses (MBGs) in cancer therapy: full of hope and promise. Mater Lett 251: 241-246.

15. Gomez Cerezo N, Izquierdo Barba I, Arcos D, Vallet Regi M (2015) Tailoring the biological response of mesoporous bioactive materials. J Mater Chem B 3(18): 3810-3819.

16. Wallace KE, Hill RG, Pembroke JT, Brown CJ, Hatton PV (1999) Influence of sodium oxide content on bioactive glass properties. J Mater Sci Mater Med 10(12): 697-701.

17. Kansal I, Reddy A, Muñoz F, Choi SJ, Kim HW, et al. (2014) Structure, biodegradation behaviour and cytotoxicity of alkali-containing alkalineearth phosphosilicate glasses. Mater Sci Eng C Mater Biol Appl 44: 159165.

18. Atkinson I, Anghel EM, Predoana L, Mocioiu OC, Jecu L, et al. (2016) Influence of $\mathrm{ZnO}$ addition on the structural, in vitro behavior and antimicrobial activity of sol-gel derived $\mathrm{CaO}-\mathrm{P}_{2} \mathrm{O}_{5}-\mathrm{SiO}_{2}$ bioactive glasses. Ceram Int 42(2): 3033-3045.

19. Atkinson I, Anghel EM, Petrescu S, Seciu AM, Stefan LM, et al. (2019) Cerium-containing mesoporous bioactive glasses: Material characterization, in vitro bioactivity, biocompatibility and cytotoxicity evaluation. Micropor Mesopor Mat 276: 76-88.

20. Hu Q Jiang W, Chen X, Li Y, Liang Q (2017) The effects of Sr concentration on physicochemical properties, bioactivity and biocompatibility of submicron bioactive glasses spheres. Adv Powder Technol 28(10): 27132722.

21. Miguez Pacheco V, de Ligny D, Schmidt J, Detsch R, Boccaccini AR (2018) Development and characterization of niobium-releasing silicate bioactive glasses for tissue engineering applications. J Eur Ceram Soc 38(3): 871-876.

22. Cacciotti I (2017) Bivalent cationic ions doped bioactive glasses: the influence of magnesium, zinc, strontium and copper on the physical and biological properties. J Mat Sci 52: 8812-8831.

23. Jalise SZ, Baheiraei N, Bagheri F (2018) The effects of strontium incorporation on a novel gelatin/bioactive glass bone graft: in vitro and in vivo characterization. Ceram Int 44(12): 14217-14227.

24. Mao L, Xia L, Chang J, Liu J, Jiang L, et al. (2017) The synergistic effects of $\mathrm{Sr}$ and $\mathrm{Si}$ bioactive ions on osteogenesis, osteoclastogenesis and angiogenesis for osteoporotic bone regeneration. Acta Biomaterr 61: 217-232.

25. Liu J, Rawlinson SC, Hill RG, Fortune F (2016) Strontium-substituted bioactive glasses in vitro osteogenic and antibacterial effects. Dental Mater 32: 412-422.

26. Zhang Q, Chen X, Geng S, Wei L, Miron RJ, et al. (2017) Nanogel based scaffolds fabricated for bone regeneration with mesoporous bioactive glass and strontium: in vitro and in vivo characterization. J Biomed Mat Res A 105(4): 1175-1183.

27. Kargozar S, Hamzehlou S, Baino F (2019) Can bioactive glasses be useful to accelerate the healing of epithelial tissues? Mater Sci Eng C 97: 10091020.

28. Rabiee SM, Nazparvar N, Azizian M, Vashaee D, Tayebi L (2015) Effect of Ion Substitution on Properties of Bioactive Glasses: A Review. Ceram Int 41(6): 7241-7251. 
29. O Donnell MD, Hill RG (2010) Influence of strontium and the importance of glass chemistry and structure when designing bioactive glasses for bone regeneration. Acta Biomat 6(7): 2382-2385.

30. Anupama M, Kumar KA, Latha JNL (2016) Role of strontium in biological system. Eur J Pharm Med Res 3(12): 177-184.

31. Meunier PJ, Roux C, Seeman E, Ortolani S, Badurski JE, et al. (2004) The effects of strontium ranelate on the risk of vertebral fracture in women with postmenopausal osteoporosis. New England journal of medicine 350(5): 459-468

32. Jensen JEB, Stang JH, Kringsholm B, Pritzl G, Sørensen OH (1997) Relationship between trace element content and mechanical bone strength. Bone 20: 104 .

33. Wu C, Zhou Y, Lin C, Chang J, Xiao Y (2012) Strontium-containing mesoporous bioactive glass scaffolds with improved osteogenic/ cementogenic differentiation of periodontal ligament cells for periodontal tissue engineering. Acta Biomater 8(10): 3805-3815.

34. Lázaro GS, Santos SC, Resende CX, dos Santos EA (2014) Individualand combined effects of the elements $\mathrm{Zn}, \mathrm{Mg}$ and $\mathrm{Sr}$ on the surface reactivity of a $\mathrm{SiO}_{2}-\mathrm{CaO}-\mathrm{Na}_{2} \mathrm{O}-\mathrm{P}_{2} \mathrm{O}_{5}$ bioglass system. J Non Cryst Solids 386: 19-28.

35. Li HC, Wang DG, Chen CZ (2015) Effect of zinc oxide and zirconia on structure, degradability and in vitro bioactivity of wollastonite Ceram Int 41(8): 10160-10169.

36. Popp JR, Love BJ, Goldstein AS (2007) Effect of soluble zinc on differentiation of osteoprogenitor cells. J Biomed Mater Res A 81(3): 766-769.

37. El Kady AM, Ali AF (2012) Fabrication and characterization of ZnO modified bioactive glass nanoparticles. Ceram Int 38(2): 1195-1204.

38. Karthika A, Kavitha L, Surendiran M, Kannan S, Gopi D (2015) Fabrication of divalent ion substituted hydroxyapatite/gelatin nanocomposite coating on electron beam treated titanium: mechanical, anticorrosive, antibacterial and bioactive evaluations. RSCAdv 54: 7341-7352.

39. Bini M, Grandi S, Capsoni D, Mustarelli P, Saino E (2009) $\mathrm{SiO}_{2}-\mathrm{P}_{2} \mathrm{O}_{5}-\mathrm{CaO}$ glasses and glass-ceramics with and without ZnO:relationships among composition, microstructure, and bioactivity. J Phys Chem C 113(20): 8821-8828.
40. Sánchez Salcedo S, Shruti S, Salinas AJ, Malavasi G, Menabue L, et al. (2014) In vitro antibacterial capacity and cytocompatibility of $\mathrm{SiO}_{2}-\mathrm{CaO}$ $\mathrm{P}_{2} \mathrm{O}_{5}$ meso macroporous glass scaffolds enriched with ZnO. J Mater Chem B 2(2): 4836-4847.

41. Shahrabi S, Hesaraki S, Moemeni S, Khorami M (2011) Structural discrepancies and in vitro nanoapatite formation ability of sol-gel derived glasses doped with different bone stimulator ions. Ceramics international 37(7): 2737-2746.

42. Goh YF, Alshemary AZ, Akram M, Abdul Kadir MR, Hussain R (2014) In vitro characterization of antibacterial bioactive glass containing ceria. Ceramics Int 40: 729-737.

43. Zhang J, Cuilian L, Yaping L, Jing S, Peng W, et al. (2010) Effect of cerium ion on the proliferation, differentiation and mineralization function of primary mouse osteoblasts in vitro. J Rare Earth 28(1): 138-142.

44. Shruti S, Salinas AJ, Lusvardi G, Malavasi G, Menabue L, et al. (2013) Mesoporous bioactive scaffolds prepared with cerium-, gallium- and zinc-containing glasses. Acta Biomater 9(1): 4836-4844.

45. Nicolini V, Malavasi G, Menabue L, Lusvardi G, Benedetti F, et al. (2017) Cerium-doped bioactive 45S5 glasses: spectroscopic, redox, bioactivity and biocatalytic properties. J Mater Sci 52: 8845-8857.

46.Zheng K, Torre E, Bari A, Taccardi N, Cassinelli C, et al. (2020) Antioxidant mesoporous Ce-doped bioactive glass nanoparticles with anti-inflammatory and pro-osteogenic activities. Materials Today Bio 5: $1-14$.

47. Nicolini V, Gambuzzi E, Malavasi G, Menabue L, Menziani MC, et al. (2015) Evidence of Catalase Mimetic Activity in $\mathrm{Ce}_{3}+/ \mathrm{Ce}_{4}+$ Doped Bioactive Glasses. J Phys Chem B 119(10): 4009-4019.

48. Hoppe A, Mouriño V, Boccaccini AR (2013) Therapeutic inorganic ions in bioactive glasses to enhance bone formation and beyond. Biomater Sci 1(3): 254-256.

49. Kalyanaraman V, Kumaravel TS, Murugan SS (2016) In vitro cytotoxicity studies of cerium oxide nanoparticles. 002E Indian Journal of Nanoscience 4(1): 1-4. 